\section{International Scientific Journal Theoretical \& Applied Science}

p-ISSN: 2308-4944 (print) e-ISSN: 2409-0085 (online)

Year: $2017 \quad$ Issue: $11 \quad$ Volume: 55

Published: $30.11 .2017 \quad$ http://T-Science.org
Bagira Algabergenovna Tulepbergenova Senior Lecturer of Propedeutics and Internal disease department

International Kazakh-Turkish University by name Yassavi, Kazakhstan bagi1958@mail.ru

Sarviniso Islamovna Ibragimova Master of medical science, lecturer of Propedeutics and Internal disease department International Kazakh-Turkish University by name Yassavi, Kazakhstan sarvinsa@mail.ru

\title{
PPREVALENCE OF HYPERCHOLESTEROLEMIA IN OBESE INDIVIDUALS LIVING IN KENTAU CITY
}

\author{
Abstract: The article considers frequency of occurrence of hypercholesterolemia in people with overweight, \\ obesity and abdominal obesity. \\ Key words: hypercholesterolemia, overweight, obesity, abdominal obesity, prevalence. \\ Language: Russian \\ Citation: Tulepbergenova BA, Ibragimova SI (2017) PPREVALENCE OF HYPERCHOLESTEROLEMIA IN \\ OBESE INDIVIDUALS LIVING IN KENTAU CITY. ISJ Theoretical \& Applied Science, 11 (55): $301-304$. \\ Soi: http://s-o-i.org/1.1/TAS-11-55-42 Doi: crossef https://dx.doi.org/10.15863/TAS.2017.11.55.42
}

\section{РАСПРОСТРАНЕННОСТЬ ГИПЕРХОЛЕСТЕРИНЕМИИ У ЛИЦ С ОЖИРЕНИЕМ ПРОЖИВАЮЩИХ В ГОРОДЕ КЕНТАУ}

Аннотация: В статье рассматривается частота встречаемости гиперхолестеринемии у лиц с избыточной массой тела, ожирением и абдоминальным ожирением.

Ключевые слова: гиперхолестеринемия, избыточный вес, ожирение, абдоминальное ожирение, распространенность.

\section{Введение.}

Сердечно-сосудистые представляют большую

заболевания социальноэкономическую проблему, так как занимают ведущее место в структуре заболеваемости и утраты трудоспособности [1]. По данным Centers for Disease Control and Prevention средняя продолжительность жизни была бы на 10 лет больше при отсутствии столь высокой распространенности этих заболеваний, охватывающих все страны и континенты [2]. По результатам проведенных многих зарубежных исследований известно, что существует тесная связь между повышенным уровнем холестерина и развитием атеросклероза. Гиперхолестеринемия является одним из основных модифицируемых факторов риска развития сердечно-сосудистых заболеваний. [3]. Еще в 1994 году ученые Law M.R., Wald N.J., Thompson S.G. в своих исследованиях показали, что риск развития ишемической болезни сердца начинает повышаться при уровне холестерина выше 180 мг/дл (4,64 ммоль/л) [4]. Наряду с этим, была установлена тесная связь между гиперхолестеринемией и ожирением. Если одни исследования говорят, что индекс массы тела (ИМТ) и показатель объема талии (ОТ) одинаково коррелируют с уровнем холестерина [5], то другие утверждают о тесной связи ИМТ и гиперхолестеринемии по сравнению с показателями ОТ [6].

Цель исследования. Целью данного исследования явилось изучение частоты встречаемости гиперхолестеринемии у лиц с избыточной массой тела (ИзМТ), ожирением и (AО) в сравнении с лицами без ИзМТ, ожирения и АО у жителей города Кентау.

Дизайн, материалы и методы исследования. Дизайн работы обусловлен одномоментным исследованием проведенном в городе Кентау. Проведен статистический анализ результатов скринингового обследования. Всего скрининговое обследование прошли 1329 лиц, из них 1077 с результатами анализа на холестерин. Таким образом, выборкой данного исследования явилась 1077 лиц, среди которых 555 (51,5\%) мужчины, 522 (48,5\%) женщины. Исследуемые были в возрасте от 40 до 64 лет, среди которых преобладала возрастная категории 45-59 лет. При 


\begin{tabular}{l|lr|ll|ll} 
& ISRA (India) & $=\mathbf{1 . 3 4 4}$ & SIS (USA) & $=\mathbf{0 . 9 1 2}$ & ICV (Poland) & $=\mathbf{6 . 6 3 0}$ \\
Impact Factor: & ISI (Dubai, UAE) $=\mathbf{0 . 8 2 9}$ & PUHI (Russia) & $=\mathbf{0 . 2 0 7}$ & PIF (India) & $=\mathbf{1 . 9 4 0}$ \\
& GIF (Australia) & $=\mathbf{0 . 5 6 4}$ & ESJI (KZ) & $=\mathbf{3 . 8 6 0}$ & IBI (India) & $\mathbf{4 . 2 6 0}$ \\
& JIF & $\mathbf{1 . 5 0 0}$ & SJIF (Morocco) & $\mathbf{2 . 0 3 1}$ & & \\
\hline
\end{tabular}

определении ИМТ категория 25-29,9 составила

наибольшую долю исследуемых.

Таблица 1

Общая характеристика исследуемых

\begin{tabular}{|c|c|c|}
\hline Изучаемые показатели & \multicolumn{2}{|c|}{$\mathbf{n = 1 0 7 7}$} \\
\cline { 2 - 3 } & $\mathbf{N}$ & \% \\
\hline Пол & 555 & $51,5 \%$ \\
мужчины & 522 & $48,5 \%$ \\
женщин & & \\
Возраст & 191 & $17,8 \%$ \\
до 45 & 707 & $65,6 \%$ \\
$\mathbf{4 5 - 5 9}$ & 179 & $16,6 \%$ \\
$\mathbf{6 0 - 7 4}$ & & \\
& & \\
ИМТ & 421 & $39 \%$ \\
$\mathbf{2 2 5}$ & 393 & $36,5 \%$ \\
$\mathbf{2 5 - 2 9 , 9}$ & 175 & $16,2 \%$ \\
$\mathbf{3 0 - 3 4 , 9}$ & 64 & $5,8 \%$ \\
$\mathbf{3 5 - 3 9 , 9}$ & 24 & $2,2 \%$ \\
$\mathbf{> 4 0}$ & & \\
& \multicolumn{2}{|}{} \\
\hline
\end{tabular}

У всех пациентов были результаты измерения роста, веса, объема талии. По результатам измерения веса и роста определяли ИМТ, по формуле вес (кг)/рост в м². Объем талии измерялся сантиметровой лентой на уровне пупка и оценивался в сантиметрах. Кроме антропометрических данных имелись результаты определения уровня холестерина в капиллярной крови.
Данные вычислены пакетом статистических программ Biostat. При статистическом расчете качественных переменных применялся $\chi^{2}$ Пирсона.

Результаты исследования.

В диаграмме 1 показан результат определения гиперхолестеринемии среди 1077 лиц, который составил $24 \%$.

Распространенность гиперхолестеринемии среди жителей города Кентау.

Диаграмма 1

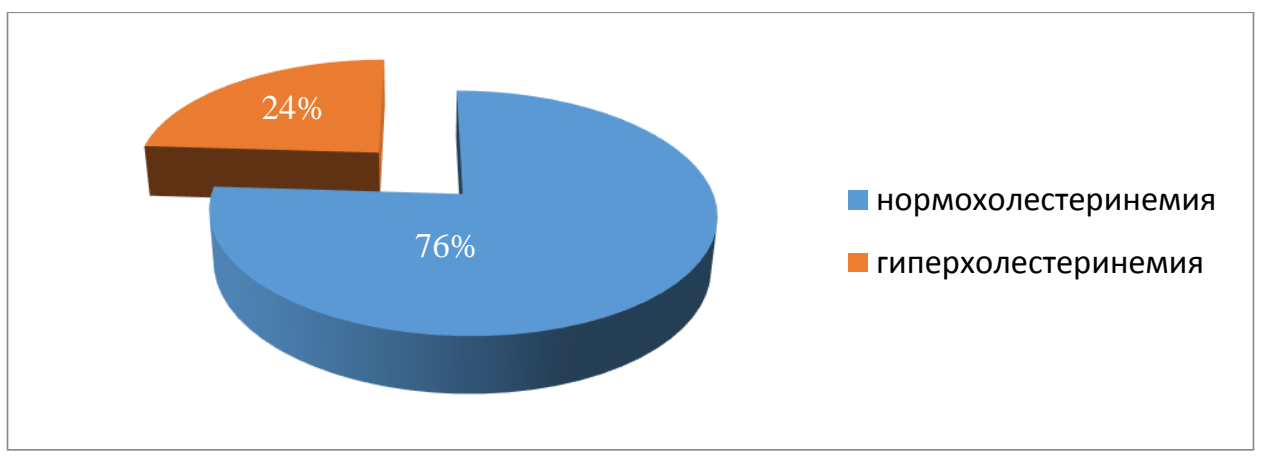

Частота

встречаемости

гиперхолестеринемии в зависимости от пола показала, что распространенность повышенного уровня холестерина выше среди женщин по сравнению по с мужчинами, что показана в талице 2. 


\begin{tabular}{l|lrl|l|ll} 
& ISRA (India) & $=\mathbf{1 . 3 4 4}$ & SIS (USA) & $=\mathbf{0 . 9 1 2}$ & ICV (Poland) & $=\mathbf{6 . 6 3 0}$ \\
Impact Factor: & ISI (Dubai, UAE) $=\mathbf{0 . 8 2 9}$ & PVHU (Russia) $=\mathbf{0 . 2 0 7}$ & PIF (India) & $=\mathbf{1 . 9 4 0}$ \\
& GIF (Australia) & $\mathbf{0 . 5 6 4}$ & ESJI (KZ) & $=\mathbf{3 . 8 6 0}$ & IBI (India) & $\mathbf{4 . 2 6 0}$
\end{tabular}

Распространенность гиперхолестеринемии в зависимости от пола.

\begin{tabular}{|c|c|c|c|c|c|}
\hline \multirow{2}{*}{ Пол } & \multicolumn{2}{|c|}{ XC $<\mathbf{5 . 2}$} & \multicolumn{2}{c|}{ XC > 5.2 } & \multirow{2}{*}{ N=1077 } \\
\cline { 2 - 5 } & $\mathrm{n}$ & $\%$ & $\mathrm{n}$ & 20 & 555 \\
\hline муж & 444 & 80 & 111 & 28 & 522 \\
\hline жен & 377 & 72 & 145 & & \\
\hline
\end{tabular}

В таблице 3 показано изучение распространенности гиперхолестеринемии в зависимости от возраста.
Частота встречаемости повышенного уровня холестерина определалась среди лиц в возрастных категориях до 45 лет, 45-59 лет, 60-74 лет.

Таблица 3

Распространенность гиперхолестеринемии в зависимости от возраста.

\begin{tabular}{|c|c|c|c|c|c|}
\hline \multirow[b]{2}{*}{ Возраст } & \multicolumn{2}{|c|}{$\mathrm{XC}<5.2$} & \multicolumn{2}{|c|}{$\mathrm{XC}>5.2$} & \multirow[t]{2}{*}{$\mathrm{N}=1077$} \\
\hline & $\mathbf{n}$ & $\%$ & $\mathbf{n}$ & $\%$ & \\
\hline До 45 лет & 160 & 83,8 & 31 & 16,2 & 191 \\
\hline $45-59$ & 535 & 75,7 & 172 & 24,3 & 707 \\
\hline $60-74$ & 126 & 70,4 & 53 & 29,6 & 179 \\
\hline
\end{tabular}

Результаты данной таблицы показывают что, по мере увеличения возраста увеличивалась частота встречаемости гиперхолестеринемии. Кроме того, в возрастной категории 60-74 лет отмечался пик распространенности повышенного уровня холестерина.

В таблице 4 представлены результаты определения распространенности гиперхолестеринемии в зависимости от ИМТ.

Таблица 4

Распространенность гиперхолестеринемии в зависимости от ИМТ.

\begin{tabular}{|c|c|c|c|c|c|}
\hline \multirow{2}{*}{ ИМТ } & \multicolumn{2}{|c|}{ XC $\mathbf{5 . 2}$} & \multicolumn{2}{c|}{ XC > 5.2 } & \multirow{2}{*}{$\mathbf{N}=\mathbf{1 0 7 7}$} \\
\cline { 2 - 5 } & $\mathrm{n}$ & $\%$ & $\mathrm{n}$ & $\%$ & 421 \\
\hline $\mathbf{2 2 5}$ & 339 & 80,5 & 82 & 19,5 & 393 \\
\hline $\mathbf{2 5 - 2 9 , 9}$ & 301 & 76,6 & 92 & 23,4 & 175 \\
\hline $\mathbf{3 0 - 3 4 , 9}$ & 121 & 69,1 & 54 & 30,9 & 64 \\
\hline $\mathbf{3 5 - 3 9 , 9}$ & 45 & 70,3 & 19 & 29,7 & 24 \\
\hline$>\mathbf{4 0}$ & 15 & 62,5 & 9 & 37,5 & \\
\hline
\end{tabular}

Как показывает результаты таблицы 4 , у лиц с ИзМТ (ИМТ 25-29,9) и ожирением (ИМТ с 30 по 40 и больше) отмечается более высокая распространенность повышенного уровня холестерина по сравнению с ИМТ <25.
В таблице 5 показаны результаты изучения частоты встречаемости гиперхолестеринемии в зависимости от показателя ОТ.

Распространенность гиперхолестеринемии в зависимости от показателей ОТ.

\begin{tabular}{|c|c|c|c|c|c|}
\hline \multirow{2}{*}{$\begin{array}{c}\text { Показатели } \\
\text { ОТ }\end{array}$} & \multicolumn{2}{|c|}{$\mathrm{XC}<5.2$} & \multicolumn{2}{|c|}{$\mathrm{XC}>5.2$} & \multirow[t]{2}{*}{$\mathrm{N}=1077$} \\
\hline & $\mathrm{n}$ & $\%$ & $\mathrm{n}$ & $\%$ & \\
\hline $\begin{array}{c}\text { OT }>94 \text { см у } \\
\text { муж } \\
\text { OT }>80 \text { см у } \\
\text { жен }\end{array}$ & 447 & 80,7 & 107 & 19,3 & 554 \\
\hline
\end{tabular}




\begin{tabular}{|c|c|c|c|c|c|c|}
\hline Impact Factor: & $\begin{array}{l}\text { ISRA (India) } \\
\text { ISI (Dubai, UAF } \\
\text { GIF (Australia) } \\
\text { JIF }\end{array}$ & $\begin{array}{l}=1.344 \\
=0.829 \\
=0.564 \\
=1.500\end{array}$ & $\begin{array}{l}\text { SIS (USA) } \\
\text { PИНЦ (Russia) } \\
\text { ESJI (KZ) } \\
\text { SJIF (Morocco) }\end{array}$ & $\begin{array}{l}=0.912 \\
=0.207 \\
=\mathbf{3 . 8 6 0} \\
=\mathbf{2 . 0 3 1}\end{array}$ & $\begin{array}{l}\text { ICV (Poland) } \\
\text { PIF (India) } \\
\text { IBI (India) }\end{array}$ & $\begin{array}{l}=6.630 \\
=1.940 \\
=4.260\end{array}$ \\
\hline
\end{tabular}

\begin{tabular}{|c|c|c|c|c|c|}
\hline \begin{tabular}{c} 
OT $\begin{array}{c}\text { 94 см у } \\
\text { муж } \\
\text { ОT }<\mathbf{8 0} \text { см y } \\
\text { жен }\end{array}$ \\
\hline
\end{tabular} & 374 & 71,5 & 149 & 28,5 & 523 \\
\hline
\end{tabular}

В нашем исследовании у лиц с АО по сравнению с лицами без АО отмечается более высокая распространенность показателя повышенного уровня холестерина.

\section{Заключение:}

1. Распространенность гиперхолестеринемии у лиц проживающих в городе Кентау составляет $24 \%$.
2. Распространенность гиперхолестеринемии высокая среди женщин по сравнению с мужчинами.

3. С увеличением возраста увеличивалась распространенность повышенного уровня холестерина.

4. У лиц с ИзМТ, ожирением и АО распространенность гиперхолестеринемии высокая по сравнению с лицами без АО и ИМТ $<25$.

\section{References:}

1. Shcherbakova E. (2011) V 2001-2009 godakh ot 56 do $58 \%$ smertey v SNG byli vyzvany boleznyami sistemy krovoobrashcheniya, ot 12 do 13\%-zlokachestvennymi novoobrazovaniyami // Demeskop Weekly. 2011.-№469-470.

2. (2017)

Available: http://who.int/mediacentre/factsheets/fs317/ru/ (Accessed: 10.11.2017).

3. Thom T., Haase N., et al. (2006) Heart disease and stroke statistic-2006 update: a report from the American Association Statistics Committee and Stroke Statistics Subcommittee // Circulation. - 2006. - Vol. 113. - P. 85-151.

4. Law M.R., Wald N.J., Thompson S.G. (1994) By how much and how quickly does reduction in serum cholesterol lower risk of ischemic heart disease? // Brit. Med. J. - 1994. - Vol. 308. - P. 367-373.

5. (2017) Donthu Kiranmayee, Kothapalli Kavya, Yalamanchali Himabindu, Correlations Between Anthropometry and Lipid Profile in Women With PCOS. J Hum Reprod Sci. 2017 Jul-Sep; 10(3): 167-172.

6. Zhi Yang, Xun Ding, Jiang Liu, Peng Duan, Lian Si, Binghua Wan, Ping Tu. (2017) Associations between anthropometric parameters and lipid profiles in Chinese individuals with age $\geq 40$ years and BMI $<28 \mathrm{~kg} / \mathrm{m} 2$. Plos. June 20, 2017. 